\title{
Wacana Islam di Facebook Jabatan-Jabatan Mufti Malaysia ${ }^{1}$
}

\author{
Islamic Discourse in the Facebook of Mufti Departments in Malaysia
}

\author{
MUHAMAD FAISAL ASHAARI*, ROSMAWATI MOHAMAD RASIT, ZAINAB ISMAIL \& \\ MOHAMMAD ISMATH RAMZY2
}

\begin{abstract}
The fatwa institution is an authoritative religious institution in issuing Islamic laws in Malaysia. However, the authoritative bodies in the virtual world are exposed to various challenges including open critiques. Until December 2018, not all departments of mufti in Malaysia are actively using Facebook, but some departments do not have Facebook account. This article analyzes the extent to which Facebook Departments of Mufti enter the public sphere, which is a form of open discussion. Therefore, this article discusses how the Departments of Mufti in Malaysia brings up the discourse about Islam on Facebook. This is a case study design using content analysis to check postings sent to Facebook. The design of this study is a case study focusing on the Facebook page of the Departments of Mufti in Malaysia. Data were collected from January to September 2018 for Facebook with less than 100 posts while those with over 100 posts were collected only from September 2018. The pro-active page in issuing Islamic laws on all issues is Wilayah Persekutuan and Perak can be considered as active. The discourse and propagation of Islamic laws through Facebook could not be much given by Mufti Departments and some of them even do not have a Facebook. The departments seem incompetent to conduct Islamic Discourse in Malaysia public sphere.
\end{abstract}

Keywords: Facebook, fatwa, mufti, religious authority, social media

Malaysia mempunyai 13 Jabatan Mufti Negeri yang merupakan badan berautoriti dalam mengeluarkan fatwa dan sebuah Majlis Fatwa di peringkat kebangsaan bagi menyelaraskan semua fatwa yang dikeluarkan oleh negeri. Institusi fatwa merupakan institusi yang rapat dengan masyarakat kerana perkataan fatwa itu sendiri merupakan pertanyaan hukum yang kebanyakannya datang dari masyarakat. Namun, berdasarkan kepada kajian yang dilakukan oleh Raihanah (2004)

\footnotetext{
${ }^{1}$ A version of this article entitled "Kedudukan Jabatan-jabatan Mufti di Malaysia dalam Facebook" has been previously published in Prosiding Nadwah Ulama Nusantara (NUN) VIII: Sinergi Ulama dalam Pemerkasaan Ummah in 2018, authored by Muhamad Faisal Ashaari, Rosmawati Mohamad Rasit \& Zulkefli Aini.

${ }^{2}$ Muhamad Faisal Ashaari* (corresponding author) Ph.D., senior lecturer at Research Centre for Dakwah and Leadership, Faculty of Islamic Studies, Universiti Kebangsaan Malaysia, 43600 BANGI, Selangor, Malaysia, email: faisal@ukm.edu.my; Rosmawati Mohamad Rasit, Ph.D., senior lecturer at Research Centre for Dakwah and Leadership, Faculty of Islamic Studies, Universiti Kebangsaan Malaysia, 43600 BANGI, Selangor, Malaysia, email: rosmawati@ukm.edu.my; Zainab Ismail, Ph.D., professor at Research Centre for Dakwah and Leadership, Faculty of Islamic Studies, Universiti Kebangsaan Malaysia, 43600 BANGI, Selangor, Malaysia, email: zinab@ukm.edu.my; Mohammad Ismath Ramzy, Ph.D., senior lecturer at Department of Educational Foundations and Humanities, Faculty of Education, Universiti Malaya, 50603 KUALA LUMPUR, Malaysia, email: ismathramzy@um.edu.my.
} 
sekitar 5\% dari 5000 orang yang menjadikan jabatan mufti sebagai rujukan. Dalam kajian terkini tentang penerimaan terhadap institusi fatwa, Ahmad Hidayat dan Che Rohaizan (2017) mendapati pelajar universiti awam (UA) serta institut pendidikan tinggi swasta (IPTS) menerima baik fatwa yang diputuskan. Keadaan ini dikaitkan dengan teknologi terkini yang digunakan sebagai medium sebaran fatwa serta penjelasan terhadap fatwa yang diberikan. Dengan ini, dari satu sudut teknologi komunikasi telah memberi kesan yang positif.

Dari sudut yang lain pula, kedatangan teknologi komunikasi turut membawa secara tidak langsung beberapa kesan yang negatif. Antaranya ia telah memberi ruang yang terbuka untuk memberi pandangan dalam segala hal termasuklah mengkritik pihak berautoriti dengan cara yang kasar. Pihak agama dan institusi fatwa termasuk dalam kategori pihak autoriti kerana aturan agama dianggap sebagai unsur paksaan yang mungkin menyebabkan seseorang berasa tidak bebas (Fewcett 2014). Kamarudin et al. (2017), telah menyenaraikan beberapa contoh pandangan dari mufti yang mencetuskan kontroversi dan mendapat kritikan dari masyarakat. Antaranya ialah pengharaman Pokemon, Fatwa Pulau Pinang, DAP sebagai 'kafir harbi', GST, Sister in Islam sebagai pertubuhan yang haram dan ratu cantik. Terdapat sesetengah pihak yang mempersoalkan kewajaran pandangan dari mufti dalam isu tersebut dan mempertikaikan keabsahannya. Malahan ada yang cuba membawa kes ke mahkamah seperti dalam fatwa tentang ESQ. Walaupun tentangan ini datang dari segelintir masyarakat sahaja berbanding dengan yang lain, tetapi boleh dikatakan bahawa ada kecenderungan masyarakat untuk menolak pandangan dari institusi agama. Artikel ini membincangkan cara Jabatan Mufti di Malaysia menguruskan penampilan mereka menerusi Facebook dan keaktifan dalam membuat posting. Ia turut membincangkan isu-isu yang diwacanakan dalam Facebook Jabatan Mufti.

\section{Jabatan Mufti di Malaysia}

Dalam sejarah perkembangan institusi fatwa di Malaysia, mufti merupakan penasihat agama kepada Raja-raja Melayu sebelum pemerintahan British lagi (Zaini 1998). Sebagai penasihat, peranan mereka sangat luas kerana ia meliputi tanggungjawab memberikan kefahaman terhadap hukum Islam, mengeluarkan fatwa termasuklah menguatkuasakan hukum syarak, menjalankan tugas-tugas keadilan, mengetuai upacara rasmi negara dan menangani pelbagai persoalan yang berlaku dalam negeri (Auni 2005). Dalam hal ini, skop tugasnya meliputi aspek pentadbiran, keagamaan dan kehakiman (Shamrahayu 2015; Mohd Hisham 2009). Dalam pada masa itu pelbagai nama diberikan kepada jawatan ini seperti mufti, kadi dan imam. Namun, untuk memastikan pentadbiran yang lebih telus pembahagian kuasa telah dibuat dan akhirnya institusi fatwa dipisahkan dari institusi kehakiman dan pentadbiran agama.

Penubuhan institusi fatwa di Malaysia dicatat dalam Undang-undang Tubuh Negeri (Zaini 1998). Ini bermakna, setiap negeri di Malaysia mempunyai seorang mufti bagi menasihati pemerintah dalam urusan yang berkaitan hukum dan mengetuai upacara rasmi. Ia juga menjadi pengerusi kepada mesyuarat untuk mengeluarkan hukum dan fatwa dalam sesuatu yang kemudiannya diwartakan selaras dengan kehendak Undang-undang Tubuh Negeri dan Undangundang Pentadbiran Hal Ehwal Islam. Dengan ini, keputusan yang dikeluarkan oleh mufti adalah keputusan rasmi kerajaan. Kedudukannya diletakkan dalam kerangka undang-undang negeri akan menjadikannya sebagai institusi yang dihormati. Menurut Muhammad Ifzal, Siddiq dan Muhammad Junaid (2015), kedudukan institusi fatwa di Malaysia yang diletakkan di bawah kerangka perlembagaan lebih baik berbanding dari Pakistan yang meletakkannya di luar. Pandangannya akan lebih dihormati dan disegani. Ia merupakan sebahagian dari pelaksanaan siyasah shar'iyyah yang berhikmah walaupun ia tidak semestinya mempengaruhi kehakiman dan perundangan (Mohd Kamel et al. 2016). 
Dalam pada itu, terdapat perbezaan dari sudut pelaksanaan antara negeri ke negeri yang lain di Malaysia. Ada negeri seperti Terengganu, Perak, Negeri Sembilan dan Pulau Pinang yang mengangkatnya sebagai ahli mesyuarat tidak tetap bagi Ahli Mesyuarat Kerajaan Negeri (EXCO). Dengan kuasa yang ada sebagai penasihat agama, peranannya sangat besar dalam mendekati dan membimbing masyarakat. Ia tidak bergerak secara keseorangan, tetapi ia telah diinstitusikan dengan maksud mempunyai pejabat dan para pembantu bagi membantu menguruskan istinbat hukum, falak, penyelidikan dan sebagainya.

\section{Jabatan Mufti di Public Sphere}

Jabatan mufti merupakan jabatan yang mempunyai autoriti untuk membuat apa-apa keputusan dalam hal ehwal agama di Malaysia. Pandangan mereka dihormati dan disegani kerana merupakan wakil kepada sultan untuk bercakap dalam soal agama. Manakala sultan pula merupakan ketua agama Islam kepada negeri atau Yang Di Pertuan Agong merupakan ketua kepada negeri yang tidak mempunyai sultan. Ini bermakna, institusi fatwa merupakan institusi yang selayaknya dihormati. Walau bagaimanapun, kedatangan media baharu telah memberi suatu cabaran kepada pihak berautoriti kerana masyarakat maya pada hari ini bukan sekadar tidak segan untuk mengatakan tidak, tetapi mereka boleh mengeluarkan kata-kata yang tidak sopan. Institusi fatwa yang sepatutnya menjadi tempat rujukan tetapi keberadaannya di alam maya menjadinya sebagai tempat yang terbuka kepada kritikan. Hal ini tidak dapat dielakkan kerana para pengkaji seperti Hairudin (2004) serta Mohd Yuszaidi dan Muammar (2015) mendapati bahawa sikap mencabar pihak autoriti merupakan fenomena yang wujud dalam alam maya.

Penolakan terhadap pihak berautoriti dengan kata-kata yang kesat bukan sekadar dihalakan kepada parti pemerintah, tetapi juga kepada institusi sultan yang menaungi rakyat secara keseluruhannya (Wan Amizah \& Muhammad Adnan 2017). Dengan erti kata yang lain, tentangan terhadap autoriti menerusi alam maya tidak dapat dielakkan. Alam maya telah membuka semua ruang perbincangan terbuka untuk semua pihak. Dengan keupayaan teknologi pada masa kini, sesuatu maklumat akan tersebar ke seluruh negara dalam tempoh yang sangat singkat. Habermas (1989; 2006) telah memperkenalkan teori public sphere yang menjelaskan bahawa perbincangan yang dilakukan di tempat yang terbuka atau di tempat awam seperti di kedai kopi tidak terhad kepada orang tertentu, tetapi ia terbuka untuk semua. Perbincangan di alam maya selari dengan konsep public sphere kerana sifat perbincangannya adalah terbuka yang boleh disertai oleh ramai orang. Habermas $(1989 ;$ 2006) menggariskan bahawa public sphere haruslah dalam keadaan perbincangan yang terbuka di mana semua pihak boleh mempunyai akses. Mereka mempunyai kebebasan yang penuh untuk menyuarakan tanpa sebarang halangan dan sekatan.

El-Nawawy dan Sahar (2010) telah menggunakan teori ini untuk membincangkan wacana tentang Islam yang terdapat dalam dua laman sesawang iaitu IslamOnline.net dan IslamWay.com. Mereka mendapati ramai pengguna muda yang aktif dengan laman sesawang ini untuk mendapatkan maklumat yang relevan dan berinteraksi dengannya. Keaktifan mereka menggunakannya boleh membentuk sebuah komuniti maya yang disebut sebagai digital ummah (Bunt 2000) atau 'virtual ummah' (Mandaville 2007) walaupun datang dari latar belakang yang berbeza dari sudut negara, bangsa dan bahasa. Keinginan mereka kepada fatwa dan pandangan agama mendorong mereka untuk pergi ke laman sesawang ini untuk berbincang dan bertukar pandangan. Namun, menurut elNawawy dan Khamis (2010), perbincangan yang terdapat dalam laman sesawang berkenaan masih belum lagi mencapai tahap kritis dan rasional seperti mana yang diteorikan oleh Habermas (1989; 2006) kerana wacananya belum cukup kritis. Ia juga masih belum lagi mencapai tahap cara yang dianjurkan oleh Islam iaitu ijtihad dan ijmak. 
Walau bagaimanapun, dalam dunia maya yang terbuka luas ini di mana semua pihak memberikan pandangan dan kritikan, malahan cemuhan dan kutukan, ada pengkaji berpandangan menjangkakan hakisan terhadap autoriti ahli agama kerana media berada di tangan semua orang manakala kawalan sukar untuk dilakukan (Turner 2007; Campbell 2007). Mereka mendakwa "siapakah yang akan bercakap bagi pihak Islam" kerana ia mungkin akan membawa kekeliruan dalam masyarakat apabila wujud pelbagai pandangan (Anderson 2003). Dengan maksud, siapakah pihak berautoriti itu kerana autoriti dalam dunia maya semakin kurang relevan apabila kawalan dan pengawasan kepada setiap individu sukar untuk dilakukan. Bagi sesetengah pengkaji, mereka mungkin berminat dengan isu kehilangan monopoli dalam agama Islam kerana mereka menjangkakan pengalaman yang sama berlaku seperti dalam agama Kristian yang berpecah kepada aliran Katolik dan Protestan.

Perkara yang sama juga timbul dalam Islam apabila wujud aliran yang dikenali sebagai Islam liberal (Khalif 2009) dan post Islamisme (Maszlee 2016) yang cuba mentafsirkan Islam yang berlainan dengan aliran yang dipegang oleh ulama yang muktabar. Begitu juga dengan cabaran kekeliruan terhadap maklumat Islam yang terlalu banyak di alam maya yang disebut sebagai kebanjiran maklumat atau overload information. Masyarakat boleh menjadi keliru untuk memilih manakah maklumat yang betul, tambahan pula keberadaan media di tangan pula mendorong mereka menyumbang sesuatu pandangan di alam maya. Namun, pengalaman cabaran terhadap autoriti bukan bermaksud hakisan terhadap kebenaran al-Quran dan hadis kerana al-Quran merupakan teks yang dijamin penjagaannya oleh Allah manakala hadis pula direkod serta dihafal oleh ramai orang Islam. Dalam pada itu, sekiranya ada orang yang mahu mentafsirkan Islam mengikut kehendak masing-masing, ia sukar dikawal kerana media di tangan masing-masing. Oleh sebab itu, ramai pengkaji mendakwa autoriti pihak berkuasa semakin mencair.

\section{Metodologi}

Reka bentuk kajian kes telah digunakan dalam kajian ini yang hanya menumpukan kepada page Facebook Jabatan-jabatan Mufti di Malaysia. Menjelang 2019, semua jabatan mempunyai page Facebook dan Pahang masih menggunakan Facebook tetapi Johor, Terengganu, Sabah dan Sarawak tidak mempunyai page dan Facebook. Pada 2018, jumlah posting dalam page Facebook banyak dan berbeza antara setiap negeri, data dikumpulkan dengan dua cara. Bagi jumlah posting yang kurang dari 100, data dikumpulkan dari Januari hingga September 2018. Ia melibatkan Jabatan Mufti Negeri Perlis, Kedah, Pulau Pinang, Perak, Selangor, Perlis dan Melaka. Manakala, bagi jumlah posting yang lebih dari 100, data dikumpulkan dari bulan September 2018 sahaja. Ia melibatkan Jabatan Mufti Negeri Sembilan, Perlis dan Wilayah Persekutuan. Unit analisis terdiri dari maksud ayat dan perenggan yang terdapat dalam posting berkenaan. Analisis dilakukan kepada dua iaitu tahap keaktifan posting dan kandungan posting. Analisis yang pertama dilakukan dengan mengira jumlah like dan posting antara Januari hingga September 2018. Perbincangan kritis dilakukan terhadap dapatan dengan membincangkan faktor yang mempengaruhi tahap keaktifan Jabatan Mufti dengan media baharu. Analisis yang kedua dilakukan dengan membahagikan posting kepada lima kategori iaitu iklan dan hebahan, berita jabatan, penjelasan hukum dan fatwa, kuliah online dan lain-lain. Dari jumlah posting yang dikumpulkan mengikut kategori, perbincangan kritis dilakukan terhadap kandungan posting, trend dan tahap responsif posting berkenaan terhadap isu semasa. 


\section{Dapatan Kajian dan Perbincangan}

Kajian ini secara khususnya membincangkan empat aspek iaitu kedudukan Jabatan Mufti di Page Facebook, kandungan page Facebook Jabatan Mufti, Unit Falak dan perbincangan kedudukan Jabatan Mufti di Facebook.

\section{Kedudukan Jabatan Mufti di Facebook}

Kedudukan Jabatan Mufti di alam maya Malaysia boleh dilihat dari dua perspektif iaitu; Laman sesawang yang menyediakan sumber maklumat yang statik berkaitan hal ehwal fatwa dan mufti di negeri berkenaan. Laman sosial yang menyediakan ruang komunikasi yang interaktif dengan masyarakat bagi mengikuti perkembangan fatwa dan mufti di negeri berkenaan. Penyertaan Jabatan Mufti dalam dunia maya merupakan suatu keperluan yang tidak boleh diabaikan. Dalam keadaan kadar tembus Internet yang tinggi di Malaysia, Jabatan Mufti tidak boleh berada di pinggiran tetapi perlu aktif dan pro-aktif dalam membangunkan Islam di alam maya.

Semua Jabatan Mufti Negeri mempunyai laman sesawang yang kebiasaannya seperti dalam Jadual 1 di bawah. Ia mempamerkan struktur organisasi, fatwa yang telah dikeluarkan, iklan dan berita terkini, borang permohonan dan lain-lain. Semua laman ini dibangunkan atas tapak laman sesawang kerajaan negeri. Kedudukannya sebagai penasihat agama kepada sultan yang merupakan ketua agama bagi sesebuah negeri memaksanya secara tidak langsung untuk menyediakan maklumat, membangunkan laman sesawang dan menguruskannya.

Jadual 1 : Kedudukan Laman Sesawang, Facebook dan Instagram Jabatan Mufti

\begin{tabular}{rlllll}
\hline \multicolumn{1}{c}{ Bil } & Jabatan Mufti & $\begin{array}{l}\text { Laman } \\
\text { Web }\end{array}$ & Page & FB & Instagram \\
\hline 1 & Perlis & Ada & $33 \mathrm{k}$ & & $117 \mathrm{k}$ \\
\hline 2 & Kedah & Ada & $6.8 \mathrm{k}$ & & \\
\hline 3 & Pulau Pinang & Ada & $6.6 \mathrm{k}$ & & \\
\hline 4 & Perak & Ada & $4 \mathrm{k}$ & \\
\hline 5 & Selangor & Ada & $7.8 \mathrm{k}$ & \\
\hline 6 & Negeri Sembilan & Ada & $53 \mathrm{k}$ & \\
\hline 7 & Melaka & Ada & $2.2 \mathrm{k}$ & \\
\hline 8 & Johor & Ada & - & \\
\hline 9 & Kelantan & & 177 & \\
\hline 10 & Terengganu & Ada & - & \\
\hline 11 & Pahang & Ada & - & 4943 & \\
\hline 12 & Sabah & Ada & - & & \\
\hline 13 & Sarawak & Ada & - & & \\
\hline 14 & Wilayah & Ada & $285 \mathrm{k}$ & \\
\hline
\end{tabular}

Sumber: Laman Sesawang dan Page Facebook Jabatan Mufti Negeri 30 September 2018 
Jadual di atas menjelaskan bahawa semua negeri mempunyai laman sesawang, tetapi tahap keaktifannya berbeza antara sebuah negeri dengan yang lain. Bagi negeri yang kurang aktif, setakat maklumat minimum yang ada boleh juga memperkenalkan Jabatan Mufti kepada umum. Namun, sepatutnya ia digunakan dengan baik untuk menonjolkan lagi fungsi dan peranan institusi yang mengeluarkan hukum agar dikenali dalam membimbing masyarakat.

Bagi Facebook pula, tidak semua Jabatan Mufti aktif dan mempunyai laman sosial ini. Sepatutnya page Facebook menjadi ruang komunikasi yang lebih interaktif dengan masyarakat dan menyediakan sumber maklumat terkini. Semua fitur page Facebook boleh menjadikan Jabatan Mufti lebih dikenali dan maklumat berkaitan lebih mudah disebarkan. Namun, tidak semua Jabatan aktif seperti dalam Jadual 1 di atas. Dari tahap keaktifan ini, institusi ini boleh dibahagikan kepada tiga kategori; pertama, tidak aktif iaitu tidak mempunyai akaun FB; kedua, aktif iaitu memiliki jumlah like hingga 8 ribu; ketiga, sangat aktif iaitu mempunyai jumlah like dari 33 ribu ke atas. Dari kategori yang aktif, tidak semua mereka mempunyai taburan posting yang sama rata. Jabatan Mufti Selangor, Pulau Pinang dan Kedah yang mempunyai like yang ramai, tetapi mempunyai jumlah posting yang sedikit. Manakala, Perak pula mempunyai like yang sedikit, tetapi ia mempunyai posting yang agak banyak. Ini dapat diperhatikan dalam Jadual 2.

Jadual 2: Jumlah Like dan Posting Facebook

\begin{tabular}{lccccc}
\hline & $\begin{array}{c}\text { Jumlah } \\
\text { like }\end{array}$ & $\begin{array}{c}\text { Jan - } \\
\text { Mac }\end{array}$ & $\begin{array}{l}\text { April - } \\
\text { Jun }\end{array}$ & $\begin{array}{c}\text { Jul - } \\
\text { Sept }\end{array}$ & Sept \\
\hline Kedah & $6.6 \mathrm{k}$ & 34 & 14 & 12 & \\
\hline Pulau Pinang & $6.6 \mathrm{k}$ & 55 & 55 & 51 & \\
\hline Perak & $4 \mathrm{k}$ & 26 & 33 & 55 & \\
\hline Selangor & $7.8 \mathrm{k}$ & 4 & 4 & 9 & \\
\hline Melaka & $2.2 \mathrm{k}$ & 32 & 27 & 60 & \\
\hline Perlis & $33 \mathrm{k}$ & & & & 39 \\
\hline $\begin{array}{l}\text { Negeri } \\
\text { Sembilan }\end{array}$ & $53 \mathrm{k}$ & & & & 131 \\
\hline Wilayah & $285 \mathrm{k}$ & & & 179 \\
\hline \multicolumn{5}{c}{ Sumber: Page Facebook Jabatan Mufti Negeri } \\
\end{tabular}

Hasil analisis menunjukkan Jabatan Mufti Perlis, Negeri Sembilan dan Wilayah merupakan jabatan yang aktif dalam menggunakan Facebook. Sepanjang September sahaja, mereka mempunyai 179 posting. Semua negeri menunjukkan posting yang sekata tetapi berbeza dengan Kedah dan Selangor. Kedah menunjukkan taburan posting yang semakin menurun dari suku tahun yang pertama hingga yang ketiga. Manakala Selangor pula menunjukkan posting yang sangat sedikit sejak dari awal tahun lagi. Pada asasnya, keaktifan dalam penggunaan media baharu secara umumnya berkaitan rapat dengan tiga faktor iaitu kehendak, alat dan kemudahan, pelaksana yang mantap dan strategi pemasaran yang baik. Faktor kehendak ialah faktor keinginan dari pihak pengurusan itu sendiri yang merupakan asas kepada sesuatu perkara. Tanpa kehendak dalaman ini, agak sukar untuk merealisasikan perkara ini biarpun ada tekanan dari luar. Dengan kehendak, pengurusan yang mantap pula diperlukan kerana ia akan bergerak dalam kumpulan. Ia melibatkan pengurusan sumber manusia yang berwibawa untuk menjalankan kerja dengan sempurna. Manakala strategi pemasaran yang baik pula ialah penggunaan teknik yang betul dalam menyempurnakan semua kerja. 
Kemungkinan kelemahan Jabatan Mufti dalam bergerak aktif di alam maya boleh dikaitkan dengan salah satu atau memiliki semua faktor yang di atas.

Wilayah Persekutuan merupakan Jabatan Mufti yang sangat aktif dalam memanfaatkan media baharu. Setakat September 2018, dengan jumlah like Jabatan Mufti WP seramai 285 ribu. Ia mempunyai gerak kerja yang tersusun hasil dari kerja berkumpulan. Menurut temu bual dengan Pegawai Jabatan Mufti Wilayah, terdapat 4 orang penyelidik secara khusus membantu menjalankan kajian dan penyelidikan untuk memastikan semua urusan istinbat dan hukum berjalan lancar. Manakala empat orang lagi pembantu penyelidik bertugas membantu penyelidikan termasuk menguruskan semua saluran media baharu meliputi Facebook, Instagram dan laman sesawang. Ini tidak termasuk kakitangan sokongan dan bahagian lain yang bertanggung jawab yang membantu melancarkan pengurusan dan pentadbiran pejabat (Tajul Urus 2018). Hampir setiap pagi Mufti akan berbincang dengan penyelidik tentang hukum dan mengemaskinikan penyelidikan yang dilakukan sehingga mereka dapat membangunkan Bayan Linnas dan lain-lain

Namun, Jabatan Mufti yang lain biasanya mempunyai seorang atau berdua yang bertanggungjawab untuk membuat kajian dan penyelidikan. Mereka digelar sebagai pegawai istinbat dan jawatan ini bersifat tetap yang dilantik oleh Suruhanjaya Perkhidmatan Awam (SPA). Menurut Tajul Urus (2018) dan Rizuan (2018), dua orang pegawai ini tidak mencukupi untuk melakukan gerak kerja penyelidikan, namun ada Jabatan yang meminta jawatan tambahan yang bersifat kontrak dari negeri atau dari Majlis Agama Islam atau dari pihak lain. Menurut Rizuan (2018), ini telah dilakukan oleh Jabatan Mufti Pulau Pinang tetapi mereka menjadikan jawatan berkenaan untuk membangunkan Unit Falak. Begitu juga dengan Jabatan Mufti Wilayah yang mendapat bantuan dari Tabung Haji bagi membiayai jawatan pegawai bagi membantu penyelidikan.

\section{Kandungan Page Jabatan Mufti di Malaysia}

Dari sudut kandungan, posting dalam page Jabatan Mufti boleh dibahagikan kepada empat kategori iaitu iklan dan hebahan, berita jabatan, penjelasan hukum dan fatwa, kuliah online dan lain-lain seperti dalam Jadual 3. Kategori ini dibina berdasarkan kepada tinjauan terhadap posting yang dilakukan dan ia sesuai dibahagikan mengikut empat kategori ini.

Jadual 3: Kandungan page Facebook Jabatan-jabatan Mufti di Malaysia

\begin{tabular}{lcccccc}
\hline & $\begin{array}{c}\text { Posting } \\
\text { Jan -Sept } \\
2018\end{array}$ & $\begin{array}{c}\text { Iklan dan } \\
\text { hebahan }\end{array}$ & $\begin{array}{c}\text { Berita } \\
\text { Jabatan }\end{array}$ & $\begin{array}{c}\text { Penjelasan } \\
\text { hukum dan } \\
\text { fatwa }\end{array}$ & $\begin{array}{c}\text { Kuliah } \\
\text { Online }\end{array}$ & $\begin{array}{c}\text { Lain- } \\
\text { lain }\end{array}$ \\
\hline Kedah & 60 & 10 & 35 & 7 & 4 & 4 \\
\hline Pulau Pinang & 161 & 21 & 107 & 17 & 9 & 7 \\
\hline Perak & 125 & 13 & 53 & 47 & 8 & 4 \\
\hline Selangor & 17 & 11 & 5 & 0 & 0 & 1 \\
\hline Melaka & 119 & 10 & 99 & 2 & 1 & 7 \\
\hline \multicolumn{6}{c}{ Sumber: Page Facebook Jabatan Mufti } \\
\\
\multicolumn{7}{c}{ Penjelasan Hukum dan Fatwa }
\end{tabular}

Dari sudut penjelasan hukum dan fatwa, terdapat Jabatan Mufti yang menggunakan medium Facebook untuk memberikan penjelasan isu-isu agama yang berlaku di negeri berkenaan dan juga di peringkat nasional. Sebagai contoh, Jabatan Mufti Perak menerusi Timbalan Mufti yang banyak 
mengemukakan penulisan dan pandangan khususnya yang berkaitan dengan isu pemikiran liberal dan termasuklah isu lesbian, gay, bisexual and transsexual (LGBT) yang heboh dibincangkan dalam kalangan masyarakat sejak kebelakangan ini. Penjelasan secara bertulis yang disebarkan menerusi media baharu sangat penting untuk memastikan kekeliruan yang berlaku mendapat penjelasan dari pihak yang berautoriti dalam agama. Namun, tidak semua jabatan mengambil inisiatif ini sebagai mana yang dijelaskan dalam Jadual 3. Jabatan Mufti Perak dan sekali sekala Pulau Pinang kelihatan yang memberi maklum balas dalam isu semasa.

Jabatan Mufti Wilayah Persekutuan (WP) sangat aktif dan pantas dalam memberikan pandangan dan penjelasan hukum menerusi media sosial khususnya dalam isu-isu yang terkini. Ini menjadikan pandangannya sering kali dinanti-nantikan oleh semua pihak dan pandangannya dihormati. Untuk itu, penjelasan secara panjang lebar dikeluarkan khususnya dalam isu yang sensitif untuk mengelak kekeliruan. Bahan yang dijelaskan di dalam laman sesawang, disebarkan di dalam page Facebook untuk tatapan umum. Ini bermakna, Jabatan Mufti WP menggunakan medium ini sebaiknya untuk mendekati masyarakat. Namun, ada Jabatan Mufti yang mempunyai fatwa yang diwartakan dan yang tidak diwartakan, tetapi menghebahkannya menerusi media sosial.

Terdapat Jabatan Mufti mempunyai fatwa yang diwartakan dan yang tidak, namun kelihatan medium Facebook tidak digunakan untuk membuat hebahan. Sebagai contoh, pada tahun 2018, Jabatan Mufti Selangor mempunyai 7 Fatwa (tidak warta) yang dikeluarkan pada 15 Januari 2018 tetapi tidak disiarkan (post) dalam page Facebook. Sekiranya hebahan dibuat menerusi media baharu, maka secara tidak langsung ia boleh memberikan penjelasan yang cepat dan sekali gus penarafan (rating) yang baik kepada Facebook. Walau pun ada kelemahan dalam menggunakan Facebook, ada negeri yang telah menggunakan cara lain untuk mendekati kumpulan sasaran. Sebagai contoh, menurut Syarbaini et al. (2018), Selangor sedang membangunkan aplikasi mobile Fatwa untuk memudahkan masyarakat mencari hukum dan fatwa. Sungguhpun demikian, hasrat untuk melihat Jabatan Mufti aktif dan responsif dengan isu semasa belum dapat dicapai lagi.

\section{Iklan dan Hebahan}

Page Facebook menyediakan fitur untuk iklan dan hebahan dalam berbagai perkara. Dengan cara ini pengguna akan boleh mendapat maklumat itu dari posting yang disebarkan dalam Facebook. Ia mungkin berbeza sekiranya maklumat itu hanya dicatat dalam laman sesawang sahaja kerana maklumat di situ tidak bersifat pro-aktif untuk mencari pembaca. Jabatan Mufti ada menggunakan Facebook untuk membuat hebahan tetapi tidak banyak sebagaimana yang tercatat dalam Jadual 1. Jabatan Mufti Pulau Pinang merupakan jabatan yang terbanyak menggunakan fitur ini iaitu 21 kali dan itu pun kebanyakannya program yang berkaitan dengan falak. Manakala jabatan lain boleh dianggap sebagai sedikit dalam membuat iklan dan hebahan.

Keaktifan sesebuah jabatan mengendalikan program dan mengambil berat dengan media baharu merupakan faktor yang mendorong jabatan membuat hebahan. Tanpa merancang sesuatu program, tiada keperluan untuk membuat hebahan. Walau bagaimanapun, iklan dan hebahan tidak semestinya dibuat berdasarkan kepada program yang dianjurkan oleh Jabatan, tetapi iklan yang berkaitan dengan hari kebesaran Islam, pergerakan matahari dan bulan untuk solat Gerhana dan sebagainya. Begitu juga fitur iklan dan hebahan tidak digunakan dengan baik apabila kurang mengambil perhatian kepada media baharu seperti tiada kakitangan yang antara skop kerjanya ialah untuk publisiti di media baharu. 


\section{Berita}

Perkembangan jabatan pula sangat baik untuk dihebahkan menerusi Facebook. Ia akan menonjolkan cara dan keaktifan sesebuah Jabatan itu bekerja. Berdasarkan kepada konsep newsworthiness, masyarakat ingin tahu berita yang ada kaitan dengan mereka, bukan sekadar berita yang berkaitan dengan hal ehwal jabatan sahaja. Ia mungkin berita bergambar mufti bersama masyarakat yang memperlihatkan kebersamaan masyarakat bersama mufti. Begitu juga berita terkini tentang fatwa, berita pergerakan matahari dan bulan dan sebagainya. Berdasarkan kepada Jadual 1, semua jabatan banyak memaparkan berita dan perkembangan jabatan menerusi page melainkan Jabatan Mufti Selangor. Ini adalah fitur yang terbanyak digunakan berbanding dengan fitur lain yang mungkin memerlukan kepada persediaan yang lebih teliti. Ringkasnya, pemberitaan yang banyak tentang aktiviti jabatan di Facebook perlu diseimbangkan dengan peranan Jabatan Mufti. Berita yang ada kepentingan dengan umum perlu lebih banyak dipamerkan berbanding dengan berita yang bersifat program dalaman seperti mesyuarat dan himpunan kakitangan.

\section{Kuliah Atas Talian}

Page Facebook menyediakan fitur live streaming yang boleh membuat rakaman kuliah secara langsung. Dengan ini segala kuliah yang disampaikan dapat dimanfaatkan sebaiknya oleh penonton. Ini merupakan antara fitur page Facebook yang istimewa kerana Jabatan Mufti boleh membuat liputan langsung kuliah agama yang disampaikan oleh mufti atau pegawainya. Secara tidak langsung ia memasyarakatkan mufti di alam maya. Kuliah yang disiarkan secara langsung ini akan diikuti sekiranya tajuk dan penyampaian yang menarik. Dalam kajian yang dilakukan oleh Miladi, Karim dan Athambawa (2017), kebanyakan responden dari Qatar mengakui bahawa siaran televisyen tentang hukum hakam telah membantu mereka memahami tentang agama. Menurut kajian ini lagi, responden mengakui kesannya masih lagi kurang berbanding dengan sekiranya mereka berdepan secara bersemuka. Walau bagaimanapun, kuliah ini sangat penting sebagai alternatif untuk mereka yang tidak dapat menghadiri kuliah secara bersemuka.

Berdasarkan kepada Jadual 3, Jabatan Mufti belum lagi manfaatkan medium ini sepenuhnya. Hanya Jabatan Mufti Pulau Pinang yang ada membuat 9 live streaming. Itu pun masih sedikit biarpun setakat September 2018, ia sebanyak 8 siri yang telah diadakan. Namun, hanya ada dua sahaja yang dibuat liputan secara langsung dalam FB. Walaupun begitu ada para mufti mempunyai medium lain selain dari Facebook rasmi jabatan untuk menyebarkan kuliah mereka. Sebagai contoh, Dr. Mohd Zulkifli al-Bakri, Mufti WP dan Dr. Mohd Asri, Mufti Perlis mempunyai page Facebook dan Instagram peribadi yang membuat liputan kuliahnya dan juga disiarkan secara langsung oleh pihak-pihak lain. Page berkenaan bukan page rasmi jabatan mufti, tetapi masyarakat terus menganggap kedua sebagai mufti dan suara yang mereka keluarkan sebagai suara sebagai seorang mufti.

\section{Kedudukan Jabatan Mufti di Alam Maya}

Secara umumnya page Facebook Jabatan-Jabatan Mufti di Malaysia masih belum lagi cukup pro-aktif di alam siber melainkan Jabatan Mufti Wilayah. Bagi yang aktif pula, penjelasan tentang hukum Islam belum lagi diketengahkan dengan baik dan aktif dalam page. Dengan kata yang lain ialah ia belum lagi memasuki public sphere seperti yang disebut oleh Habermas. Dengan ini perbincangan secara kritis, terbuka dan membina antara institusi fatwa dan masyarakat masih belum lagi diwujudkan. Keadaan ini tidak semestinya mencerminkan jabatan mufti tidak aktif di alam realiti tetapi ini berkaitan dengan penglibatan secara aktif di alam maya. Dalam masa yang sama, ia tidak 
menggambarkan kedudukan perbincangan tentang Islam di Malaysia tidak aktif. Terdapat beberapa kajian yang menggambarkan perbincangan Islam di Malaysia berlaku secara kritis dan terbuka sehingga tahap cemuhan, kutukan dan sebagainya (Siti Maimunah 2015; Siti Nazifatul 2015; Mohd Azmir 2017). Terdapat banyak laman forum, blog, Facebook dan sosial media yang lain telah menyumbang kepada perbincangan secara maya yang aktif. Tumpuan kajian ini ialah tentang kedudukan jabatan mufti di Malaysia.

Kebimbangan tentang jabatan mufti yang mungkin terdedah dengan kritikan yang terbuka tidak perlu timbul kerana penjelasan hukum secara ilmiah, berhikmah dan berfakta menjadikan ia sebagai suatu pandangan yang dihormati. Apatah lagi sekiranya pandangan itu dikeluarkan menerusi perbincangan dan kajian yang dilengkapi dengan fakta yang kukuh. Solahuddin, Kamarudin, Mohd Akram (2018) ada mencadangkan model penilaian yang boleh menjadikan sesebuah fatwa itu diterima baik yang akhirnya pandangan dari institusi ini tidak dipertikaikan lagi. Inti pati kepada model ini ialah pandangan yang diberikan itu dirumuskan melalui penyelidikan dan perbincangan para ulama yang disimpulkan dengan penuh teliti.

Ini dapat dilihat dari posting yang dikemukakan dalam Page Facebook Jabatan Mufti Wilayah. Setakat ini Mufti Wilayah, Dr. Zulkifli al-Bakri memberikan pandangan yang disokong dengan penghujahan yang terperinci dari sudut nas dan fakta. Ia dikemaskan lagi dengan penghujahan yang dikeluarkan secara berhikmah dan tidak menimbulkan kontroversi. Ini secara tidak langsung menjadikannya sebagai tokoh ilmuwan yang disegani. Begitu juga dengan pandangan yang dikemukakan oleh Jabatan Mufti Perak berkaitan dengan isu liberalisme. Menerusi Timbalan Mufti yang banyak memberikan pandangan berkaitan dengan pemikiran ini, kelihatan ia telah diterima dengan baik oleh masyarakat. Tidak terdapat penentangan secara terbuka mungkin kerana pemikiran liberal secara umumnya tidak diterima oleh masyarakat Islam di Malaysia.

Berdasarkan kepada analisis page Facebook, banyak posting tentang berita, hebahan dan iklan manakala posting yang berkaitan dengan penjelasan isu semasa sangat tidak banyak. Terdapat dua pendekatan yang boleh dilakukan oleh Jabatan Mufti sama ada bersifat pro-aktif dan reaktif. Proaktif ialah mufti memberi pandangan dalam sesuatu perkara tanpa mengambil kira pandangan yang lain sehingga mungkin menentang arus atau timbul perbezaan dalam pandangan. Dari satu sudut, pendekatan ini positif kerana ia memintas dari pihak lain memberi pandangan yang tersasar tetapi dari sudut yang lain ia mungkin dilihat separa matang dan gopoh sekiranya tidak hati-hati. Namun, pandangan yang mungkin berbeza dengan pihak lain, tidak semestinya membawa kepada konflik jika ia dikemukakan dengan bijaksana kerana institusi fatwa merupakan institusi yang disegani dan dihormati. Manakala, pendekatan reaktif ialah dengan cara 'tunggu dan lihat' sehingga semua pihak memberi pandangan, baru mufti memberi pandangan yang bersifat kesimpulan terhadap keseluruhan pandangan yang diberikan. Ia adalah pendekatan yang berhati-hati, tetapi ketika ketiadaan pandangan dari pihak berautoriti masyarakat Islam akan mencari pandangan orang lain sehingga apabila mereka berpegang dengan sesuatu pandangan, ia sukar untuk diubah.

Kesimpulannya, alam maya merupakan medan yang penting untuk dikuasai oleh golongan agama khususnya Jabatan Mufti kerana ia merupakan alam yang turut didiami oleh manusia pada hari ini. Sikap malu media atau 'shy media' perlu dielakkan dan Jabatan Mufti perlu bergerak proaktif dalam media baharu sejajar dengan generasi baharu pada masa kini yang mempunyai budaya hidup dalam jaringan. Jabatan Mufti tidak perlu bimbang dengan cabaran di public sphere iaitu pandangan dan kritikan yang terbuka sekiranya memberikan penjelasan secara ilmiah dan berhikmah. Kedudukan Jabatan Mufti di alam maya boleh diperkasakan dengan mengukuhkan unit yang berkaitan dengan teknologi maklumat dan dokumentasi. Ini boleh diperkasakan menerusi Unit Maktabah yang ada dalam kebanyakan Jabatan Mufti dengan tambahan kakitangan yang bekerja 
secara lebih fokus sesuai dengan perkembangan zaman yang menuntut perubahan dalam gaya bekerja.

Implikasi dari itu ialah, Jabatan Mufti boleh memperkasakan dirinya di alam maya dengan mengukuhkan unit yang berkaitan dengan teknologi maklumat dan dokumentasi. Kakitangan di jabatan ini yang berkeupayaan membuat penyelidikan dalam hukum hakam dan bidang teknologi maklumat perlu diramaikan. Ia boleh dilakukan dengan menggunakan struktur yang sedia ada seperti Unit Maktabah yang ada dalam kebanyakan Jabatan Mufti atau membuat struktur baharu untuk kerja yang lebih fokus sesuai dengan perkembangan zaman yang menuntut perubahan dalam gaya bekerja. Kajian masa depan dalam bidang ini ialah tentang cara masyarakat menerima dan mendapat maklumat yang diperlukan dalam isu-isu agama dari institusi agama, selebriti dan tokoh agama.

\section{Acknowledgement}

This article is an output of researches under grant schemes of Cabaran Perdana DCP-2017-013/3 and KOMUNITI 2012-002.

\section{References}

Anderson, Jon W. 2003. New media, new publics: reconfiguring the public sphere of Islam. Social Research 70(3): 887-907.

Ahmad Hidayat Buang \& Che Rozaihan Che Rosli. 2017. Persepsi dan penerimaan mahasiswa terhadap fatwa negeri Selangor. Journal of Fatwa Management and Research 9:129-147.

Auni Abdullah. 2005. Tradisi Pemerintahan Islam dan Kolonialisme dalam Sejarah Alam Melayu. Kuala Lumpur: Darul Fikir Sdn. Bhd.

Campbell, H. 2007. Who's got the power? Religious authority and the internet. Journal of Computer Mediated-Communication 12(3): 1043-1062.

Fewcett, Edmund. 2014. The Life of an Idea. New Jersey: Princeton University Press.

Habermas, Jürgen. 2006. Religion in Public Sphere. European Journal of Philosophy 14(1): 1-25.

Habermas, Jürgen. 1989. The Structural Transformation of the Public Sphere: An Inquiry into a Category of Bourgeois Society. Cambridge Massachusetts: The MIT Press.

Hairudin Harun. 2004. Retorik Sains dan Teknologi di Malaysia. Kuala Lumpur: Dewan Bahasa dan Pustaka.

Kamarudin Ahmad, Solahuddin Abdul Hamid, Mohd Akram Dato' Dahaman@Dahlan Azman Md Zain, Mohd Nizho Abdul Rahman \& Zulhilmi Paidi. 2017. Reaksi Masyarakat Terhadap Keputusan Fatwa Berdasarkan Model Penilaian Kickpatrick. Journal of Islamic, Social, Economics and Development 2(6): 363-371.

Khalif Muammar. 2009. Atas Nama Kebenaran: Tanggapan Kritis Terhadap Wacana Islam Liberal. Bangi: Institut Alam dan Tamadun Melayu, Universiti Kebangsaan Malaysia.

Mandaville, P., 2007. Globalization and the politics of religious knowledge: pluralizing authority in the Muslim world. Theory, Culture \& Society 24(2): 101-115.

Maszlee Malik. 2016. Pasca Islamisme atau Wacana Baru Gerakan Islam. Generasi kedua Politikal Islam: Wacana Baru Gerakan Islam. Jil. 1. Petaling Jaya, Selangor: Ilham Books.

Miladi, Noureddine; Karim, Saleh \& Athambawa, Mahroof. 2017. Fatwa on satellite TV and the development of Islamic religious discourse. Journal of Arab \& Muslim Media Research 10(2): 129-152. 
Mohammed el-Nawawy and Sahar Khamis. 2010. collective edentity in the virtual public sphere: contemporary discourses in two Islamic websites. The International Communication Gazette 72(3): 229-250.

Mohd Azmir Maideen. 2017. Analisis propaganda Syiah menerusi Facebook di Malaysia. Tesis Sarjana. Universiti Kebangsaan Malaysia.

Mohd Hisham Mohd Kamal. 2009. Office of the mufti in Malaysia: legal history and constitutional role. Shariah Law Reports 3: 20-43.

Mohd Kamel Mat Salleh, Mohd al Adib Samuri dan Mohd Izhar Ariff Mohd Kashim. 2016. Kedudukan fatwa dan pendapat mufti sebagai autoriti di Mahkamah Syariah Malaysia. Journal of Contemporary Islamic Law 1(1): 1-26.

Mohd Yuszaidi Mohd Yusoff \& Muammar Ghaddaffi Hanafiah. 2015. Impak media baharu terhadap sistem nilai masyarakat Melayu di Malaysia. Jurnal Komunikasi 31(2): 33-46.

Muhammad Ifzal Mehmood, Siddiq Ali Chishti and Muhammad Junaid Mughal. 2015. Islamic concept of fatwa, practice of fatwa in Malaysia and Pakistan: the relevance of Malaysian fatwa model for legal system of Pakistan. International Research Journal of Social Sciences 4(9): 46-51.

Raihanah Abdullah. 2004. Fatwa dan masyarakat. In. Ahmad Hidayat Buang (ed.). Fatwa di Malaysia. Kuala Lumpur: Jabatan Syariah dan Undang-undang, Akademik Pengajian Islam, Universiti Malaya.

Rizuan Mohd Idrus. 2018. Peranan Jabatan Mufti Pulau Pinang. Temubual.

Shamrahayu A. Aziz. 2015. Institusi Fatwa dalam Perundangan Negara. Kuala Lumpur: Institut Kefahaman Islam Malaysia

Siti Maimunah Kahal. 2015. Interaksi antara agama menerusi Facebook: Kajian terhadap Facebook Murtads in Malaysia and Singapore. Tesis Sarjana. Universiti Kebangsaan Malaysia.

Siti Nazifatul Hayat. 2015. Analisis keganasan siber menerusi Facebook murtads in Malaysia and Singapore. Tesis Sarjana. Universiti Kebangsaan Malaysia.

Solahuddin Abdul Hamid, Kamarudin Ahmad \& Mohd Akram Dahaman@Dahlan. 2018. Kedinamikan penyampaian fatwa negeri-negeri di Malaysia: penilaian adaptasi berdasarkan "kirkpatrick model of evaluation. Manu 27: 97-116.

Syarbaini Ahmad, Khirul Nizam Ab Rahman, Mokmin Basri \& Noor Azli Mohamed Masrup. 2018. Development of mobile fatwa application for the Selangor State of Mufti Department. International Research Journal of Electronics \& Computer Engineering IRJECE 4(1): 7-10.

Tajul Urus Abdul Halim. 2018. Peranan Jabatan Mufti Wilayah Persekutuan. Temubual.

Turner, B. S., 2007. Religious authority and the new media. Theory, Culture \& Society 24(2): 117-134.

Wan Amizah Wan Mahmud \& Muhammad Adnan Pitchan. 2017. Media baharu dan institusi raja di Malaysia: kes penghinaan raja-raja di media sosial. Jurnal Komunikasi 37(1): 406-422.

Zaini Nasohah. 1998. Perkembangan Pentadbiran Undang-Undang Islam di Malaysia Sehingga Tahun 1990-an. Bangi: Universiti Kebangsaan Malaysia. 